\title{
Vitamin D status in non-supplemented postmenopausal Taiwanese women with osteoporosis and fragility fracture
}

\author{
Jawl-Shan Hwang ${ }^{1}$, Keh-Sung Tsai ${ }^{2}$, Yuh-Min Cheng ${ }^{3}$, Wen-Jer Chen ${ }^{4}$, Shih-Te Tu ${ }^{5}$ Ko-Hsiu Lu ${ }^{6}$, Sheng-Mou Hou', \\ Shu-Hua Yang ${ }^{8}$, Henrich Cheng ${ }^{9}$, Hung Jen Lai ${ }^{10}$, Sharon Lei ${ }^{10}$ and Jung-Fu Chen ${ }^{11^{*}}$
}

\begin{abstract}
Background: Vitamin D is essential for calcium metabolism, Vitamin D deficiency can precipitate osteoporosis, cause muscle weakness and increase the risk of fracture. The aim of this study was to assess the prevalence of vitamin D inadequacy among non-supplemented postmenopausal women with osteoporosis and fragility fractures of the hip or vertebrae in Taiwan.

Methods: This multi-center, cross-sectional, observational study analyzed the vitamin D inadequacy [defined as 25 $(\mathrm{OH})$ D level less than $30 \mathrm{ng} / \mathrm{mL}$ ] in Taiwanese postmenopausal osteoporotic patients who suffered from a low trauma, non-pathological fragility hip or vertebral fracture that received post-fracture medical care when admitted to hospital or at an outpatient clinic.

Results: A total of 199 patients were enrolled at 8 medical centers in Taiwan; 194 patients met the study criteria with 113 (58.2\%) and 81 (41.8\%) patients diagnosed with hip and vertebral fracture, respectively. The mean serum $25(\mathrm{OH})$ D level was $21.1 \pm 9.3 \mathrm{ng} / \mathrm{mL}$, resulting in a prevalence of vitamin $\mathrm{D}$ inadequacy of $86.6 \%$ of the patients.

Conclusions: High prevalence of vitamin D inadequacy across all age groups was found among non-supplemented women with osteoporosis and fragility hip or vertebral fracture in Taiwan.
\end{abstract}

Keywords: Vitamin D, Osteoporosis, Fracture

\section{Background}

Osteoporosis is a progressive systemic bone disease characterized by low bone mass and microarchitecture deterioration of bone tissue, leading to increased bone fragility and susceptibility to fracture. It is recognised as a major public health problem in many countries, as well as in Taiwan [1,2]. The fractures associated with osteoporosis cause physical disability, reduced quality of life and high mortality in the aging population [3,4]. Several therapeutic options are available for the treatment or prevention of osteoporosis [5,6], and some of these drugs were proven to be efficacious and safe in Taiwanese population studies [7-10]. Among the osteoporosis management factors,

\footnotetext{
* Correspondence: chenjf56090@gmail.com

${ }^{11}$ Division of Endocrinology and Metabolism, Department of Internal Medicine, Chang Gung Memorial Hospital, Chang Gung University, 123, Ta-Pei Road, Niao-Sung Hsiang, Kaohsiung, Taiwan

Full list of author information is available at the end of the article
}

vitamin D plays an important role $[11,12]$. Vitamin $\mathrm{D}$ is absorbed from food or synthesized in skin that is exposed to sunlight. The liver converts it to 25-hydroxyvitamin D $[25(\mathrm{OH}) \mathrm{D}]$, which in turn is converted by the kidney to active form calcitriol $1,25(\mathrm{OH})_{2} \mathrm{D}$. Vitamin D increases serum calcium by promoting intestinal calcium absorption and plays a role in bone formation and resorption [13]. Synthesis of 1, 25-dihydroxyvitamin D $\left[1,25(\mathrm{OH})_{2} \mathrm{D}\right]$ is stimulated by both PTH and hypophosphatemia. Vitamin D deficiency is associated with secondary hyperparathyroidism, which stimulates bone resorption, thus increasing the rate of bone loss and the risk of fractures [14]. In addition, vitamin D deficiency is associated with muscle weakness and postural instability, leading to an increased risk of falls [15], which may lead to fractures. However, vitamin D status associated with fractures has not been investigated in the Taiwanese population. The objective of this study was to evaluate the prevalence of vitamin D 
inadequacy among postmenopausal women with osteoporosis and fragility fractures of the hip or vertebrae in Taiwan.

\section{Methods Study design}

This multi-center, cross-sectional, observational study was conducted in 8 medical centers in Taiwan. Among hip fracture patients, only those requiring hospitalization for postfracture medical treatment were enrolled in this study while vertebral fracture patients were enrolled from an outpatient clinic, for a 12-month period between September 1, 2010 and September 1, 2011. The study protocol was approved by the Institutional Review Board of Chang Gung Memorial Hospital Linkou and Kaohsiung, National Taiwan University Hospital, Kaohsiung Medical University Chung-Ho Memorial Hospital, Changhua Christian Hospital, Chung Shan Medical University Hospital, Shin Kong Wu Ho-Su Memorial Hospital, and Taipei Veterans General Hospital, prior to initiation of the study and all patients gave written informed consent before any study procedure was performed. The study was conducted in compliance with the current revision of the Helsinki Declaration and in accordance with the Good Clinical Practice guidelines.

\section{Study subjects}

The centers recruited postmenopausal women aged 50 years and over with a recent low-trauma fragility vertebral fracture at outpatient clinic or hip fracture inpatient care. Low-trauma fractures were defined as fractures resulting from falls from standing height. Recent fracture was defined as hip fracture or related clinical signs/symptoms occurring within 30 days of the study enrollment date; vertebral fracture or related clinical signs/symptoms occurring within 3 months of the study enrollment date. Fracture was confirmed by radiograph or X-ray report; categorization of vertebral fracture was assessed centrally.

Patients who had secondary osteoporosis or other diseases which could affect bone metabolism, significant hepatic or renal diseases [defined as serum alanine aminotransferase $(\mathrm{ALT})>3$ times upper limit of normal $(\mathrm{ULN})$, and creatinine $(\mathrm{Cr})>1.6 \mathrm{mg} / \mathrm{dL}]$, malignant neoplasm, major trauma (e.g. automobile accident) or recent use of drugs known to affect bone metabolism were excluded. Patients who participated in a clinical trial for osteoporosis within the past 3 years, had low trauma fracture of sites other than the hip or vertebrae, mentally or legally incapacitated or unable to answer healthrelated questions were also excluded as well as patients with premature or surgical menopause, e.g. oophorectomy due to ovarian cancer, or patients who have regularly been receiving $2800 \mathrm{IU}$ vitamin D supplement per week or 400 IU vitamin D supplement per day at study enrollment.

\section{Study procedures}

Patients were required to have a physical examination, lateral radiographs of the thoracic and lumbar spine for vertebral fracture patients group, documentation of past medical history and concomitant medications that affect vitamin $\mathrm{D}$ metabolism, any use of anti-osteoporotic therapies, pre-fracture daily activity and health-related questionnaire. A single, non-fasting blood sample to assess $25(\mathrm{OH}) \mathrm{D}$ and other biochemical tests were performed in the study visit. Vitamin D inadequacy was defined as serum $25(\mathrm{OH})$ D level less than $30 \mathrm{ng} / \mathrm{mL}$. Considering prior vitamin D studies definitions [12,16-18], we further dissected vitamin $\mathrm{D}$ inadequacy into insufficiency as 25 $(\mathrm{OH}) \mathrm{D} 10$ to $30 \mathrm{ng} / \mathrm{mL}$ and deficiency as $25(\mathrm{OH}) \mathrm{D}<$ $10 \mathrm{ng} / \mathrm{mL}$. In addition to this, a cut-point of $25(\mathrm{OH}) \mathrm{D}$ less than $20 \mathrm{ng} / \mathrm{mL}$ was also analyzed to allow comparison with some recent studies.

The radiographs were performed according to a standardized protocol. A visual semiquantitative grading of vertebral fractures was performed, based on the criteria of Genant et al., by a radiologist in a centralized way. Bone mineral density (BMD) measured by dual energy X-ray absorptiometry of lumbar spine and/or hip were recorded.

Biochemical measurements were standardized using central laboratory tests method.

Serum calcium, phosphate, and creatinine were measured by automated standard laboratory methods. Intact PTH (i-PTH) was measured by ADVIA Centaur chemilluminescence instruments (SIEMENS Healthcare, Tarrytown, New York), 25-OH Vitamin D Total by chemilluminescence (Diasorin, MN, USA). The inter-assay variations for the three-level controls for assays i-PTH were $6.55 \%$, $6.02 \%$ and $5.0 \%$, and $25(\mathrm{OH}) \mathrm{D}$ two level controls $6.06 \%$ and $6.15 \%$, respectively. Bone turnover markers were measured in all patients with Bone Alkaline Phosphatase (BAP), by chemilluminescence using Beckman Access II (Fullerton, California) with inter-assay variations for the markers were $4.62 \%$ and $5.13 \%$.

\section{Statistical analysis}

Data management and analysis were performed using the SAS 8.2 (SAS Institute Inc., Cary, NC, USA) and SPSS 20.0 (IBM., USA). The prevalence of vitamin D inadequacy was analyzed; insufficiency and deficiency were also summarized. Age and fracture site stratified prevalence of vitamin D insufficiency and deficiency were also calculated. Data were presented as mean \pm SD for continuous variables, the number and the proportions were shown for categorical variables. 
Student $\mathrm{t}$ test, Wilcoxon rank sum test or Analysis of variance (ANOVA) were used to examine the differences between/among groups for continuous variables upon the data distribution, and chi-square test or Fisher's exact test were used for categorical variables. Meanwhile, Pearson correlation was used to assess the correlation between serum vitamin $D$ levels versus fracture risk factors in these patients. All significance tests were twotailed with $p=0.05$.

\section{Results}

A total of 199 subjects were evaluated for inclusion with 194 subjects meeting all of the eligibility criteria as shown in Figure 1. Five subjects were excluded due to renal or liver impairment (4 subjects with $\mathrm{Cr}>1.6 \mathrm{mg}$ / $\mathrm{dL}$ and 1 subject with ALT $>3$ times ULN). The demographics and characteristics of the patients are shown in Table 1. Overall, the average age was 77.6years (range: 52 to 103 years) and the mean BMI was $23.9 \mathrm{~kg} / \mathrm{m}^{2}$. The mean years since menopause were 27.4 with a minimum of 5 years and maximum of 51 years. There was no difference of BMD at any site between the hip and vertebral fractures group.

The patient characteristics showed little difference between the hip and vertebral fracture group. Among 113 hip and 81 vertebral fracture women, the average age was 79.5years in hip fracture women while it was 74.6 years in vertebral fracture women. Regarding the co-morbidity survey, only hypertension revealed a statistical difference $(p=$ 0.033 ) between the groups, with $63.7 \%$ of the hip fracture women diagnosed with hypertension compared to $51.9 \%$ of the vertebral fracture group. Also, food composition in terms of daily vitamin D source showed some differences between groups. Among several types of calcium-rich and vitamin-containing food, including milk, yolk, cod-liver oil, fatty fish, and mushroom, the hip fracture group had higher proportion of women taking cod-liver oil and eating more fatty fish and mushrooms (46.9\% vs. $27.2 \%)$ than the vertebral fracture group.

Overall, the mean level of $25(\mathrm{OH})$ D was $21.1 \pm$ $9.3 \mathrm{ng} / \mathrm{mL}$, ranging from 4.0 to $57.5 \mathrm{ng} / \mathrm{mL}$ (median: 20.0, Q1:15.7, Q3:26.2). The prevalence of vitamin D inadequacy with serum $25(\mathrm{OH})$ D level lower than $30 \mathrm{ng} / \mathrm{mL}$ was $86.6 \%$ of the subjects. Further dissection, vitamin $\mathrm{D}$ insufficiency $[25(\mathrm{OH}) \mathrm{D} 10-30 \mathrm{ng} / \mathrm{mL}]$ prevalence was $77.8 \%$ while vitamin D deficiency [25(OH) D $<10 \mathrm{ng} / \mathrm{mL}]$ was $8.8 \%$ of the subjects (Table 2). Additionally, when using another cut-off point of $25(\mathrm{OH}) \mathrm{D}<20 \mathrm{ng} / \mathrm{mL}$, the prevalence was $49.5 \%$, as shown in Table 3.

There was no statistically significant difference in the mean $25(\mathrm{OH}) \mathrm{D}$ levels between hip and vertebral fractures subjects, 20.5 vs. $22.0 \mathrm{ng} / \mathrm{mL}$, respectively $(p=0.279$;

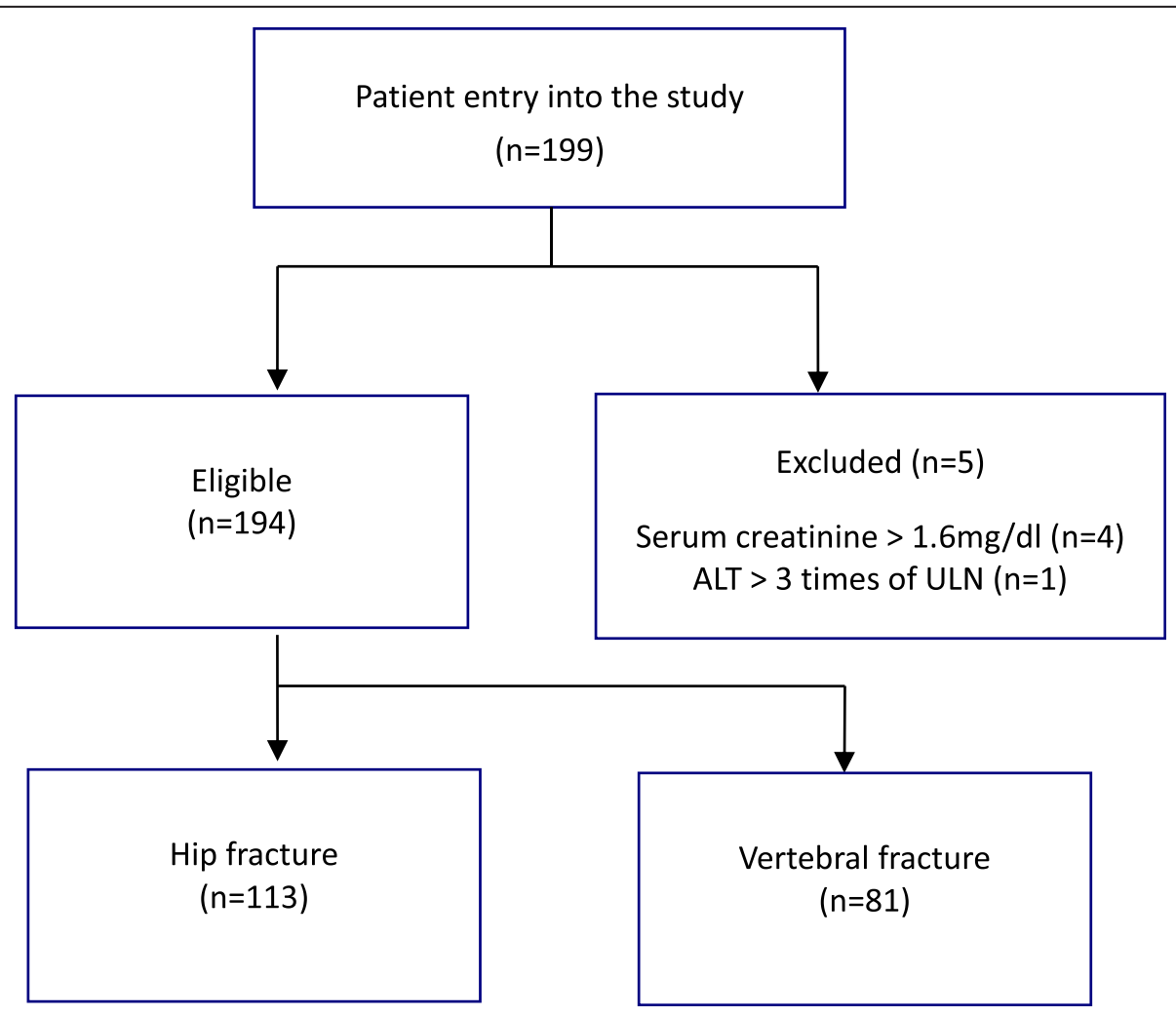

Figure 1 Patient distribution in the study. 
Table 1 Patients' characteristics

\begin{tabular}{|c|c|c|c|}
\hline & Hip fracture $(n=113)$ & Vertebral fracture $(n=81)$ & $p$-value \\
\hline Age (years), mean $\pm S D$ & $79.5 \pm 9.3$ & $74.6 \pm 8.5$ & $<0.01$ \\
\hline Height $(\mathrm{cm})$, mean $\pm \mathrm{SD}$ & $152.9 \pm 5.9$ & $150.7 \pm 6.1$ & 0.015 \\
\hline Weight (kg), mean $\pm S D$ & $55.0 \pm 10.1$ & $55.6 \pm 10.8$ & 0.688 \\
\hline $\mathrm{BMI}(\mathrm{kg} / \mathrm{m} 2)$, mean $\pm \mathrm{SD}$ & $23.5 \pm 4.1$ & $24.4 \pm 3.9$ & 0.153 \\
\hline Year of menopause, mean \pm SD & $28.3 \pm 10.5$ & $26.1 \pm 8.5$ & 0.156 \\
\hline \multicolumn{4}{|l|}{ BMD (T-score), mean \pm SD } \\
\hline Spine L1-4 & $-2.7 \pm 1.6$ & $-3.0 \pm 1.4$ & 0.383 \\
\hline Femoral neck & $-3.2 \pm 0.9$ & $-3.2 \pm 1.0$ & 0.986 \\
\hline Total hip & $-2.9 \pm 1.0$ & $-2.6 \pm 1.1$ & 0.149 \\
\hline \multicolumn{4}{|l|}{ Co-morbidity $(n, \%)$} \\
\hline Hypertension & $72(63.7 \%)$ & $42(51.9 \%)$ & 0.033 \\
\hline Diabetes & $27(23.9 \%)$ & $17(21.0 \%)$ & 0.634 \\
\hline Stroke & $5(4.4 \%)$ & $5(6.2 \%)$ & 0.742 \\
\hline Parkinson's disease & $2(1.8 \%)$ & $1(1.2 \%)$ & 1.000 \\
\hline \multicolumn{4}{|c|}{ Calcium and Vitamin D containing food $(n, \%)$} \\
\hline Milk & $73(64.6 \%)$ & $44(54.3 \%)$ & 0.149 \\
\hline Yolk & $95(84.1 \%)$ & $66(81.5 \%)$ & 0.773 \\
\hline Cod-liver oil/fatty fish/mushrooms & $53(46.9 \%)$ & $22(27.2 \%)$ & 0.005 \\
\hline
\end{tabular}

Table 4). In terms of serum markers, in the hip fracture group, there were significantly higher mean i-PTH levels (45.7 vs. $35.8 \mathrm{pg} / \mathrm{mL}$ ), lower mean serum calcium (8.2 vs. $8.9 \mathrm{mg} / \mathrm{dL}$ ), lower mean serum phosphorus (3.5 vs. $4.2 \mathrm{mg} / \mathrm{dL}$ ) and lower mean BAP levels (13.0 vs. $18.2 \mathrm{mg} /$ dL) compared to vertebral fracture group (Table 4). Serum creatinine and alanine aminotransferase were similar between the groups. The mean vitamin D levels were slightly higher but no statistical difference in summer and fall than in winter and spring season.

When analyzing the mean serum $25(\mathrm{OH})$ D levels and prevalence using three cut-off points $(<30,<20$ and $<$ $10 \mathrm{ng} / \mathrm{mL})$ by different age groups $(<60 ; 60 \sim 69 ; 70 \sim 79$; $80 \sim 84 ; \geq 85$ years), the results were consistent across all age groups with no statistical difference in the vitamin D levels or proportion of patients with vitamin $\mathrm{D}$ levels lower than $30 \mathrm{ng} / \mathrm{mL}, 20 \mathrm{ng} / \mathrm{mL}$ or $10 \mathrm{ng} / \mathrm{mL}$ in any of the age groups (Table 5).

Table 2 Distribution of serum $25(\mathrm{OH})$ D level in 194 enrolled subjects

\begin{tabular}{lccc}
\hline & $\mathbf{n ~ ( \% )}$ & Mean (SD) & $\begin{array}{c}\text { Range } \\
\text { (Min, Max) }\end{array}$ \\
\hline Adequacy $[\geq 30 \mathrm{ng} / \mathrm{ml}]$ & $26(13.4 \%)$ & $37.6(7.2)$ & $(30.0,57.5)$ \\
Inadequacy $[<30 \mathrm{ng} / \mathrm{ml}]$ & $168(86.6 \%)$ & $18.6(6.5)$ & $(4.0,29.7)$ \\
Insufficiency $[10-30 \mathrm{ng} / \mathrm{ml}]$ & $151(77.8 \%)$ & $20.0(5.3)$ & $(10.0,29.7)$ \\
Deficiency $[<10 \mathrm{ng} / \mathrm{ml}]$ & $17(8.8 \%)$ & $6.4(1.6)$ & $(4.0,9.3)$ \\
\hline
\end{tabular}

\section{Discussion}

This is the first study to examine the prevalence of vitamin $\mathrm{D}$ inadequacy among osteoporotic women with fragility hip or vertebral fracture in Taiwanese population. The results of this study have shown a high prevalence of vitamin $\mathrm{D}$ inadequacy (insufficiency and deficiency) across all age groups among women with fragility hip or vertebral fracture in Taiwan. Some studies conducted in Taiwan and Asia have shown nearly half of healthy, middle-aged and elderly women had vitamin D inadequacy, nearly onethird of adults with frailty syndrome had vitamin D insufficiency $[19,20]$ and inadequacy levels are more common in some Asian countries than in other regions [21].

International Osteoporosis Foundation recommends that a minimum level of $30 \mathrm{ng} / \mathrm{mL} \mathrm{25(OH)} \mathrm{D} \mathrm{is} \mathrm{necessary} \mathrm{in}$ older adults to reduce the risk of falls and fractures [15]. Some guidelines suggest a 25(OH) D level of at least $20 \mathrm{ng} /$ $\mathrm{mL}$ to promote intestinal calcium absorption, avoid secondary hyperparathyroidism and minimize the risk of fracture [22]. In our study, the prevalence of vitamin D insufficiency,

Table 3 Prevalence of serum 25(OH) D levels using three cut-off points

\begin{tabular}{lccc}
\hline & $<\mathbf{1 0} \mathbf{~ n g} / \mathbf{m l}$ & $<\mathbf{2 0} \mathbf{n g} / \mathbf{m l}$ & $<\mathbf{3 0} \mathbf{n g} / \mathbf{m l}$ \\
\hline Overall $(\mathrm{n}=194)$ & $17(8.8 \%)$ & $96(49.5 \%)$ & $168(86.6 \%)$ \\
Hip fracture $(\mathrm{n}=113)$ & $12(10.6 \%)$ & $60(53.1 \%)$ & $99(87.6 \%)$ \\
Vertebral fracture $(\mathrm{n}=81)$ & $5(6.2 \%)$ & $36(44.4 \%)$ & $69(85.2 \%)$ \\
\hline
\end{tabular}

NS between fracture types. 
Table 4 Biochemical parameters

\begin{tabular}{lccc}
\hline & $\begin{array}{c}\text { Hip fracture } \\
(\mathbf{n}=\mathbf{1 1 3})\end{array}$ & $\begin{array}{c}\text { Vertebral fracture } \\
(\mathbf{n}=\mathbf{8 1})\end{array}$ & p-value \\
\hline Serum 25(OH) D (ng/ml) & $20.5 \pm 9.9$ & $22.0 \pm 8.4$ & 0.279 \\
i-PTH(pg/ml) & $45.7 \pm 29.2$ & $35.8 \pm 19.4$ & 0.005 \\
Calcium (mg/dl) & $8.2 \pm 0.6$ & $8.9 \pm 0.5$ & 0.000 \\
Phosphorus (mg/dl) & $3.5 \pm 1.0$ & $4.2 \pm 2.2$ & 0.004 \\
BAP (mg/dl) & $13.0 \pm 6.9$ & $18.2 \pm 9.3$ & 0.000 \\
\hline
\end{tabular}

Data are expressed as mean \pm standard deviation.

$25(\mathrm{OH})$ D level lower than $30 \mathrm{ng} / \mathrm{mL}$, was $86.6 \%$ and the prevalence of $25(\mathrm{OH}) \mathrm{D}$ lower than $20 \mathrm{ng} / \mathrm{mL}$ was $49.5 \%$. As compared to the National Health and Nutrition Examination Survey (NHANES) 2005 to 2006, where 41.6\% of adults had $25(\mathrm{OH}) \mathrm{D}$ below $20 \mathrm{ng} / \mathrm{mL}$ [23], in the current study we have found a higher proportion of vitamin D insufficiency (49.5\%, vs. $41.6 \%)$, probably due to inclusion of subjects with confirmed fragility fracture either admitted to hospital or from outpatient clinics and due to exclusion of patients taking vitamin D supplementation regularly (2800 IU vitamin D per week or $400 \mathrm{IU}$ vitamin D per day). The results were consistent with the previous findings that low vitamin D levels were associated with a high hip fracture rate [24] and other osteoporotic fractures, including vertebral and wrist fractures [25]. One recent study has shown that among patients admitted to a rehabilitation facility, $49.1 \%$ had $25(\mathrm{OH})$ D levels below $20 \mathrm{ng} / \mathrm{mL}$ and $83 \%$ lower than $30 \mathrm{ng} / \mathrm{mL}$ [26], which is consistent with the current study results. Another study in the literature has shown $68 \%$ of hypo-vitaminosis D in an orthogeriatric rehabilitation ward within 7 days after hip fracture [27].

Vitamin D plays an important role in protein synthesis and the regulation of calcium transport which affects muscle strength as well as the balance among neurons and muscle. This might be the reason why vitamin D deficiency has been associated with muscle weakness and postural instability, leading to an increased risk of falls, which may lead to fractures $[28,29]$. Low vitamin D levels are also associated with decline in physical performance in the elderly [30].

The relationship of $25(\mathrm{OH}) \mathrm{D}$ level and i-PTH is consistent with previous reports that the synthesis and metabolism of vitamin D is coupled to calcium homeostasis and is regulated by PTH, serum calcium and phosphorus levels [12]. When hypocalcaemia occurs, serum PTH concentration increases and enhances reabsorption of calcium. In our study, serum $25(\mathrm{OH}) \mathrm{D}$ was inversely correlated with serum i-PTH $(r=-0.22, p<0.01)$.

The possible explanations for the high prevalence of vitamin D insufficiency in this cohort of Taiwanese women could be several. First, the Recommended Dietary Allowance (RDA) of vitamin D for the elderly is 800 international units per day after age 71 [22], but only $17.5 \%$ subjects have vitamin D supplements in daily life and larger-dose preparations of ergocalciferol or cholecalciferol are rare in Taiwan. Second, the consumption of fatty fish, vitamin D-fortified foods and vitamin D supplements also influence the status of vitamin D insufficiency $[31,32]$. This is the largest source of dietary vitamin D in many countries, but fortified milk, cereals and bread products with vitamin $\mathrm{D}$ in Taiwan are rarely found. Therefore, vitamin D from dietary source might be limited due to less options and lower availability of vitamin D-containing food in addition to decreased intestinal absorption of vitamin D in elderly patients. Third, the vitamin D status depends on the available amount of ultraviolet light from sunlight which varies with latitude and season; use of sunscreen and clothing; and amount of sunlight exposure which increases vitamin D concentration [33]. Although Taiwan is situated at latitude between 23 and 25 degrees, sun-avoidance behavior, skin covering and the use of sunscreen products in the Taiwanese population interfere with production of vitamin $\mathrm{D}$ in the skin. In addition, the serum vitamin $\mathrm{D}$ level has been shown to decrease with aging, with the skin of those older than 70 years of age being less efficient in converting 7- dehydrocholesterol into vitamin $\mathrm{D}$ as compared to younger individuals, impairing dermal biosynthesis of vitamin D [34].

There are some limitations of the current study. The sample size of this study $(\mathrm{n}=194)$ was relatively small although well spread and distributed throughout the island. Also, this study did not include healthy subjects without fractures or male gender as normal controls. Another limitation was the study design which did not allow us to collect vitamin D levels at the exact time of

Table 5 Mean serum 25(OH) D levels and prevalence in different age groups

\begin{tabular}{lcccc}
\hline & $<\mathbf{1 0} \mathbf{~ n g / m l}$ & $<\mathbf{2 0} \mathbf{~ n g} / \mathbf{m l}$ & $<\mathbf{3 0} \mathbf{~ n g} / \mathbf{m l}$ & $\mathbf{2 5 ( O H ) ~ D ~ l e v e l ~ ( m e a n ~} \pm$ SD) \\
\hline$<60$ y/o $(n=2)$ & $0(0 \%)$ & $0(0 \%)$ & $2(100 \%)$ & $23.3 \pm 1.7$ \\
$60 \sim 69$ y/o $(n=36)$ & $3(8.3 \%)$ & $17(47.2 \%)$ & $29(80.6 \%)$ & $22.5 \pm 10.4$ \\
$70 \sim 79$ y/o $(n=64)$ & $4(6.3 \%)$ & $33(51.6 \%)$ & $61(95.3 \%)$ & $20.4 \pm 7.9$ \\
$80 \sim 84$ y/o $(n=41)$ & $3(7.3 \%)$ & $24(58.5 \%)$ & $34(82.9 \%)$ & $21.5 \pm 10.3$ \\
$\geq 85$ y/o $(n=46)$ & $7(15.2 \%)$ & $21(45.7 \%)$ & $38(82.6 \%)$ & $20.2 \pm 9.3$ \\
\hline
\end{tabular}

NS among age groups. 
fracture; however, it was not expected that levels of vitamin D would vary significantly in the short period of time stipulated for blood collection after fracture.

\section{Conclusions}

High prevalence of vitamin D insufficiency and deficiency was found among post-menopausal women with osteoporosis and fragility hip or vertebral fracture in the Taiwanese population. Recommendations and public education for postmenopausal women with osteoporosis to receive adequate vitamin D supplementation should be reinforced.

\section{Competing interests}

Dr. Hung-Jen Lai \& Ms. Sharon Lei are the employees of Merck Sharp \& Dohme (I.A.) Corp. Taiwan Branch. All other authors declare that they have no competing interests.

\section{Authors' contributions}

JSH, KST, HJL, SL and JFC were responsible for study conception and design, drafting the manuscript. YMC, WJC, STT, KHL, SMH, SHY and HC were responsible for data analysis. All authors were responsible for discussing and interpreting the results and writing the final version to be published. All authors read and approve the final manuscript.

\section{Acknowledgments}

The authors appreciate the support from Drs. Jih-Yang Ko , Lih-Huei Chen, Yu-Yao Huang, Miao-Chen Liu, Chen-Ti Wang, Chung-Hwan Chen, Jeng-Fu Kuo, Ching-Fang Li and Wen-Cheng Huang for patient enrollment and follow-up; Dr. Chao-Jan Wang for the radiography central reading; and Merck Sharp \& Dohme (I.A.) Corp. Taiwan Branch for the funding, data analysis and technical assistance.

\section{Author details}

'Division of Endocrinology and Metabolism, Department of Internal Medicine, Chang Gung Memorial Hospital, Chang Gung University, Linkou, Taiwan. ${ }^{2}$ Department of Laboratory Medicine, National Taiwan University Hospital, College of Medicine, National Taiwan University, Taipei, Taiwan. ${ }^{3}$ Department of Orthopaedic Surgery, Kaohsiung Medical University Chung-Ho Memorial Hospital, Kaohsiung, Taiwan. ${ }^{4}$ Department of Orthopedics, Chang Gung Memorial Hospital, Chang Gung University, Linkou, Taiwan. ${ }^{5}$ Division of Endocrinology and Metabolism, Department of Internal Medicine, Changhua Christian Hospital, Changhua, Taiwan. ${ }^{6}$ Department of Orthopedics, Chung Shan Medical University Hospital, Taichung, Taiwan. ${ }^{7}$ Department of Orthopedics, Shin Kong Wu Ho-Su Memorial Hospital, Taipei, Taiwan. ${ }^{8}$ Department of Orthopaedic Surgery, National Taiwan University Hospital, Taipei, Taiwan. ${ }^{9}$ Neurological Institute, Taipei Veterans General Hospital, Taipei, Taiwan. ${ }^{10}$ Medical Department, Merck Sharp \& Dohme (I.A.) Corp. Taiwan Branch, Taipei, Taiwan. ${ }^{11}$ Division of Endocrinology and Metabolism, Department of Internal Medicine, Chang Gung Memorial Hospital, Chang Gung University, 123, Ta-Pei Road, Niao-Sung Hsiang, Kaohsiung, Taiwan.

Received: 27 January 2014 Accepted: 14 July 2014

Published: 28 July 2014

\section{References}

1. Cummings SR, Melton LJ: Epidemiology and outcomes of osteoporotic fractures. Lancet 2002, 359:1761-1767.

2. Tsai KS, Tai TY: Epidemiology of osteoporosis in Taiwan. Osteoporos Int 1997, 7(Suppl 3):96-98.

3. Center JR, Nguyen TV, Schneider D, Sambrook PN, Eisman JA: Mortality after all major types of osteoporotic fracture in men and women: an observational study. Lancet 1999, 353:878-882.

4. Cooper C: The crippling consequences of fractures and their impact on quality of life. Am J Med 1997, 103(2A):12S-17S.

5. Cranney A, Guyatt G, Griffith L, Wells G, Tugwell P, Rosen C, Osteoporosis Methodology Group and The Osteoporosis Research Advisory Group: Meta-analyses of therapies for postmenopausal osteoporosis. IX:
Summary of meta-analyses of therapies for postmenopausal osteoporosis. Endocr Rev 2002, 23:570-578.

6. Chapuy MC, Arlot ME, Duboeuf F, Brun J, Crouzet B, Arnaud S, Delmas PD, Meunier PJ: Vitamin D3 and calcium to prevent hip fractures in the elderly women. N Engl J Med 1992, 327(23):1637-1642.

7. Hwang JS, Tu ST, Yang TS, Chen JF, Wang CJ, Tsai KS: Teriparatide vs. calcitonin in the treatment of Asian postmenopausal women with established osteoporosis. Osteoporos Int 2006, 17:373-378.

8. Hwang JS, Chen JF, Yang TS, Wu DJ, Tsai KS, Ho C, Wu CH, Su SL, Wang CJ, Tu ST: The effects of strontium ranelate in Asian women with postmenopausal osteoporosis. [Erratum appears in Calcif Tissue Int. 2009 Apr;84(4):334]. Calcif Tissue Int 2008, 83:308-314.

9. Hwang JS, Liou MJ, Ho C, Lin JD, Huang YY, Wang CJ, Tsai KS, Chen JF: The effects of weekly alendronate therapy in Taiwanese males with osteoporosis. J Bone Miner Metab 2010, 28:328-333.

10. Hwang JS, Chin LS, Chen JF, Yang TS, Chen PQ, Tsai KS, Leung PC: The effects of intravenous zoledronic acid in Chinese women with postmenopausal osteoporosis. J Bone Miner Metab 2011, 29:328-333.

11. Lips $P$, van Schoor NM: The effect of vitamin D on bone and osteoporosis. Best Pract Res Clin Endocrinol Metab 2011, 25:585-591.

12. Dawson-Hughes B, Mithal A, Bonjour JP, Boonen S, Burckhardt P, Fuleihan GE, Josse RG, Lips P, Morales-Torres J, Yoshimura N: IOF position statement: vitamin D recommendations for older adults. Osteoporos Int 2010, 21:1151-1154.

13. Lips P: Vitamin D, physiology. Prog Biophys Mol Biol 2006, 92:4-8.

14. Lips $P$, Bouillon $R$, van Schoor NM, Vanderschueren $D$, Verschueren $S$, Kuchuk N, Milisen K, Boonen S: Reducing fracture risk with calcium and vitamin D. Clin Endocrinol (Oxf) 2010, 73:277-285.

15. Pfeifer M, Begerow B, Minne HW: Vitamin D and muscle function. Osteoporos Int 2002, 13:187-194.

16. Rosen CJ: Clinical practice. Vitamin D insufficiency. N Eng/ J Med 2011, 364:248-254.

17. Mithal A, Wahl DA, Bonjour JP, Burckhardt P, Dawson-Hughes B, Eisman JA El-Hajj FG, Josse RG, Lips P, Morales-Torres J, IOF Committee of Scientific Advisors (CSA) Nutrition Working Group: Global vitamin D status and determinants of hypovitaminosis D. [Erratum appears in Osteoporos Int. 2009 Nov; 20 (11):1821]. Osteoporos Int 2009, 20:1807-1820.

18. El-Hajj FG: Vitamin D deficiency in the Middle East and its health consequences. Clin Rev Bone Miner Metab 2009, 7:77-93.

19. Tsai KS, Hsu SH, Cheng JP, Yang RS: Vitamin D stores of urban women in Taipei: effect on bone density and bone turnover, and seasonal variation. Bone 1997, 20:371-374.

20. Chang $\mathrm{Cl}$, Chan DC, Kuo KN, Hsiung CA, Chen CY: Vitamin D insufficiency and frailty syndrome in older adults living in a Northern Taiwan community. Arch Gerontol Geriatr 2010, 50(Suppl 1):17-21.

21. Lim SK, Kung AW, Sompongse S, Soontrapa S, Tsai KS: Vitamin D inadequacy in postmenopausal women in Eastern Asia. Curr Med Res Opin 2008, 24:99-106.

22. Holick MF, Binkley NC, Bischoff-Ferrari HA, Gordon CM, Hanley DA, Heaney RP, Murad MH, Weaver CM, Society E: Evaluation, treatment, and prevention of vitamin D deficiency: an Endocrine Society clinical practice guideline. J Clin Endocrinol Metab 2011, 96:1911-1930.

23. Forrest KY, Stuhldreher WL: Prevalence and correlates of vitamin $D$ deficiency in US adults. Nutr Res 2011, 31:48-54.

24. Cauley JA, Lacroix AZ, Wu L, Horwitz M, Danielson ME, Bauer DC, Lee JS, Jackson RD, Robbins JA, Wu C, Stanczyk FZ, LeBoff MS, Wactawski-Wende J, Sarto G, Ockene J, Cummings SR: Serum 25-hydroxyvitamin D concentrations and risk for hip fractures. Ann Intern Med 2008, 149:242-250.

25. Van Schoor NM, Visser M, Pluijm SMF, Kuchuk N, Smit JH, Lips P: Vitamin D deficiency as a risk factor for osteoporotic fractures. Bone 2008, 42:260-266.

26. Shinchuk LM, Morse L, Huancahuari N, Arum S, Chen TC, Holick MF: Vitamin $\mathrm{D}$ deficiency and osteoporosis in rehabilitation inpatients. Arch Phys Med Rehabil 2006, 87:904-908

27. Sahota O, Gaynor K, Harwood RH, Hosking DJ: Hypovitaminosis D and 'functional hypoparathyroidism'-the NoNoF (Nottingham Neck of Femur) study. Age Ageing 2001, 30:467-472.

28. Bischoff-Ferrari HA, Dietrich T, Orav EJ, Hu FB, Zhang Y, Karlson EW, Dawson-Hughes B: Higher 25-hydroxyvitamin D concentrations are associated with better lower-extremity function in both active and inactive persons aged $>$ or $=60 \mathrm{y}$. Am J Clin Nutr 2004, 80:752-758.

29. Visser M, Deeg DJ, Lips P, Longitudinal Aging SA: Low vitamin D and high parathyroid hormone levels as determinants of loss of muscle strength 
and muscle mass (sarcopenia): the Longitudinal Aging Study

Amsterdam. J Clin Endocrinol Metab 2003, 88:5766-5772.

30. Wicherts IS, van Schoor NM, Boeke AJ, Visser M, Deeg DJ, Smit J, Knol DL,

Lips P: Vitamin D status predicts physical performance and its decline in older persons. J Clin Endocrinol Metab 2007, 92:2058-2065.

31. Holden JM, Lemar LE: Assessing vitamin D contents in foods and supplements: challenges and needs. Am J Clin Nutr 2008, 88:551S-553S.

32. Ross AC: The 2011 report on dietary reference intakes for calcium and vitamin D. Public Health Nutr 2011, 14:938-939.

33. Binkley N, Novotny R, Krueger D, Kawahara T, Daida YG, Lensmeyer G, Hollis BW, Drezner MK: Low vitamin D status despite abundant sun exposure. J Clin Endocrinol Metab 2007, 92:2130-2135.

34. MacLaughlin J, Holick MF: Aging decreases the capacity of human skin to produce vitamin D3. J Clin Invest 1985, 76:1536-1538.

doi:10.1186/1471-2474-15-257

Cite this article as: Hwang et al:: Vitamin D status in non-supplemented postmenopausal Taiwanese women with osteoporosis and fragility fracture. BMC Musculoskeletal Disorders 2014 15:257.

\section{Submit your next manuscript to BioMed Central and take full advantage of:}

- Convenient online submission

- Thorough peer review

- No space constraints or color figure charges

- Immediate publication on acceptance

- Inclusion in PubMed, CAS, Scopus and Google Scholar

- Research which is freely available for redistribution 